\title{
Is plant biodiversity driven by decomposition processes? An emerging new theory on plant diversity
}

\author{
S. Mazzoleni ${ }^{1,5}$, G. Bonanomi ${ }^{1}$, F. Giannino ${ }^{2}$, M. Rietkerk ${ }^{3}$, S. C. Dekker ${ }^{3}$ \\ and F. Zucconi ${ }^{4}$
}

${ }^{1}$ Dipartimento di Arboricoltura, Botanica e Patologia Vegetale, University of Naples Federico II, Naples, Italy.

${ }^{2}$ Dipartimento di Ingegneria Agraria e Agronomia del Territorio University of Naples Federico II, Naples, Italy

${ }^{3}$ Department of Environmental Sciences, Utrecht University, PO Box 80115, 3508 TC Utrecht, The Netherlands

${ }^{4}$ Dipartimento di Scienze Ambientali e delle Produzioni Vegetali, University Polytechnic of Marche, Ancona, Italy

${ }^{5}$ Corresponding author.E-mail: stefano.mazzoleni@unina.it.Tel. +39081 7754850, Fax +390817760104

Keywords: Allelopathy, Environmental gradient, Forest tree diversity, Intraspecific competition, Litter, Monospecific stand, Phytotoxicity, Plant-soil negative feedback.

\begin{abstract}
Diversity of forest trees ranges from monospecific stands to the astonishing richness of tierra firma tropical forests. Such patterns are observed along gradients of latitude, altitude, soil fertility and rainfall. So far, the proposed coexisting mechanisms do not provide a comprehensive and unequivocal explanation of these patterns at the community level. We propose a new theory linking species diversity with organic matter cycle and negative plant-soil feedback induced by litter autotoxicity. This approach focuses on resource-waste rather than resource-only dynamics. High diversity does occur where litter decomposition is rapid and ecosystem nutrient cycles are closed. On the other hand, single species dominance is found where litter decomposition is slow and/or autotoxicity is removed from the nutrient cycle pathway. Unlike previous theoretical views, the one we present proves potentially capable of explaining differences in species diversity both along environmental gradients and within the tropics.
\end{abstract}

\section{Introduction}

As early recognized (Darwin 1862, Hutchinson 1958), tree forest species richness shows large variations in different biomes, ranging from either monospecific or species poor forests at high latitude, through intermediate diversity in temperate plant communities, to the extremely diverse tropic environments (Hubbell 2001, Willig et al. 2003). Within the tropics, tree alpha diversity can vary from stable monospecific mangroves, through species poor stands of gallery riparian forests (Richards 1996), to the astonishing floristic richness of low-land tierra firma forests (Valencia et al. 1994, Givnish 1999). This enormous variability has been both fascinating and frustrating for plant ecologists who proposed a plethora of species coexistence mechanisms attempting to explain the processes underpinning such diversity patterns (Palmer 1994, Willig et al. 2003). Different hypotheses included equilibrium mechanisms through niche partition- ing (Tilman 1994); non-equilibrium coexistence dynamics (Huston 1994) related to disturbance (Connell 1978), predation and biotic interactions (Janzen 1970, Wills et al. 1997); fluctuations of environmental conditions (Chesson 2000); and balance between immigration/speciation and extinction (McArthur and Wilson 1967, Hubbell 2001). So far, there is little consensus on the relative importance of these processes in different plant communities. In any case, none of the proposed mechanisms provides a satisfactory explanation for all the observed tree diversity patterns.

In this paper we propose a new theory that seems to be able to explain the tree alpha diversity patterns, at both global and local scales. This is achieved by linking the biogeochemical organic matter cycle to the occurrences of negative plant-soil feedback. In this note, some background processes are reviewed and then brought together to illustrate the logical bases of a new model. 


\section{Plant-soil negative feedback}

Negative plant-soil feedback is defined as the rise of negative conditions for plant vegetative and reproductive performances induced in the soil by the plants themselves. Ancient evidences of this phenomenon are well known for agro-ecosystems, where it has been referred as 'soil sickness' or "replant disease problem" (Zucconi 1996, Miller 1996). To find any herbaceous plantations or orchards that do not experience the consequences of negative feedback when cultivated in monoculture and monosuccession is a hard challenge.

Several studies have demonstrated the pervasiveness of negative plant-soil feedback in natural plant communities. This has been reported for coastal sand dunes during primary succession (Van der Putten et al. 1993), secondary succession and temperate grasslands (Bever 1994, Klironomos 2002, Bonanomi et al. 2005b), and temperate (Streng et al. 1989, Packer and Clay 2000) and tropical forests (Webb et al. 1967, Kiers et al. 2000). In a literature survey, reported as Appendix to this paper, we found 138 experimental cases of plant-soil negative feedback on terrestrial ecosystems, but none for flowering plants and algae in marine and freshwater environments Appendix 1).

Four main mechanisms have been proposed to explain plant-soil negative feedback: soil nutrient depletion (Berendse 1994, Ehrenfeld at al. 2005), the build-up of soilborne pathogen populations (De Rooij-van Der Goes 1995, Packer and Clay 2000), the changing composition of soil microbial communities (Bever 1994, Klironomos 2002, Kardol et al. 2007), and the release of phytotoxic compounds during organic matter decomposition (Webb et al. 1967, Singh et al. 1999, Armstrong and Armstrong 2001). In our review (Appendix 1), 31.9\% of the cases of negative feedback were ascribed to litter autotoxicity. Negative feedback escape strategies depend on life form and propagation patterns. For instance, perennial clonal plants can move away by vegetative growth (Van der Putten 2003), while trees and shrubs can avoid the "home" soil (sensu Bever 1994) via seed dispersion, thus producing a Janzen-Connell distribution of seedling emergence (Packer and Clay 2000). Negative plant-soil feedback has been demonstrated to be strongly species-specific and mainly affecting individuals of the same species (Oremus and Otten 1981, Van der Putten et al. 1993, Bever 1994, Singh et al. 1999, Klironomos 2002, Bonanomi and Mazzoleni 2005, Kardol et al. 2007).

\section{Phytotoxicity of decaying litter}

Many studies reported on the phytotoxic effects of decaying plant materials (review in Rice 1984 and Blum et al. 1999). However, during decomposition, both the abundance and the activity of phytotoxic compounds continuously change over time by their sorption and polymerisation on soil organic matter and clay minerals (Makino et al. 1996), and because of the chemical transformation by microorganisms (Blum et al. 1999). This was explicitly assessed by Harper (1977) in a review of allelopathy, who pointed out that plant-produced phytotoxic compounds, being rapidly degraded by the soil microbial activity into non-toxic molecules, should have a limited expected impact on plant population dynamics. Moreover, studies of allelopathy in field conditions are rare and their interpretability has been limited by the lack of comparative experimental bioassays (Inderjit and Callaway 2003).

A renewed interest in this issue followed the work of Bonanomi et al. (2006) showing not only a widespread occurrence of phytotoxicity in decaying plant litter, but also predictable dynamics in relation to both the decomposition duration and the environmental conditions. Although different levels of litter phytotoxicity were observed for different plant functional groups (nitrogen fixer $>$ forbs $=$ woody $>>$ grasses-sedges), all tested species $(n=25)$ showed consistent patterns of phytotoxicity dynamics, with a rapid decrease in aerobic conditions, but sharp increase and stabilization of toxicity in anaerobic conditions. We are currently doing in depth experimental investigations on the prevalence of autotoxicity compared to generic phytotoxicity of decaying litter. Based on our experiments so far (Bonanomi et al. 2006; unpublished data) and evidenced by other published literature (Appendix 1), we propose that autotoxicity is a general phenomenon, and stronger than phytotoxic effects on other species, thus largely affecting ecosystem stability, productivity and diversity.

Despite the availability of mineralized nutrients, the root colonization of decomposing plant litter can require several weeks for herbaceous species (about 35 days for many grasses; reviewed by Hodge 2004), but even months for temperate forest trees under field conditions (Conn and Dighton 2000). This sharply contrasts with observations of roots actively proliferating within few days into enriched patches of mineral nutrients (Jackson and Caldwell 1989), but it is consistent with the phytotoxicity of decomposing litter.

\section{An emerging theory: litter autotoxicity links decomposition processes with species coexistence}

Decomposition of plant litter is a key ecosystem process for carbon and nutrients cycling. The factors affecting the decomposition rates and the related dynamics of nutrients have been investigated in depth in relation to both 
environmental conditions and litter chemical characteristics (Aerts 1997, Berg and McClaugherty 2003). We suggest that the view of plant litter as a nutrient source, without inclusion of the phytotoxicity concept, is limiting because the simultaneous release of nutrients and phytotoxicity during decomposition can produce unavoidable constraints to plant growth. The potential consequences of these concepts are relevant in the context of plant community organization.

The proposed new theory is based on two interlinked ideas:

1. decaying litter produces autotoxic effects, and

2. the impact of autotoxicity is dependent on the litter decaying-rate.

\section{Litter autotoxicity}

While allelopathy seems an obvious consequence of natural selection (i.e. the capacity of killing competitors), apparently the existence of autotoxicity poses a paradox: why a plant species should harm it-self and its own offsprings? Density-dependent regulation of population to avoid overcrowding has been one of the explanations (McNaughton 1968, Singh et al. 1999, Perry et al. 2005). Our view is radically different.

All living organisms such as bacteria, fungi, algae and animals produce, by their metabolisms of resources, catabolites and wastes. Why higher plants should be an exception? The interesting point is that catabolic wastes that are often toxic for the producing species can be a resource for other species at the same time. Motile species and sessile organisms that live in regularly flushed systems (e.g. aquatic environments) avoid autotoxicity because wastes are either placed away or removed by water. In contrast, for terrestrial plants autotoxicity accumulates in close proximity of the producing individual after leaf and root litter deposition, producing in turn negative feedback on plant growth.

An important consequence of the occurrences of autotoxic induced negative feedback on conspecific is the reduction of individual's vigor and dominance over more competitive species, in favor of other species, thus enhancing coexistence. Model studies implemented these concepts and demonstrated how negative feedback can affect both the spatial organization and the species diversity of plant communities (Bever et al. 1997, Bonanomi et al. 2005a).

Bertness and Leonard (1997) cleverly argued that if the occurrence, the strength and the consequences of an ecological process are not predictable, ecologists may be

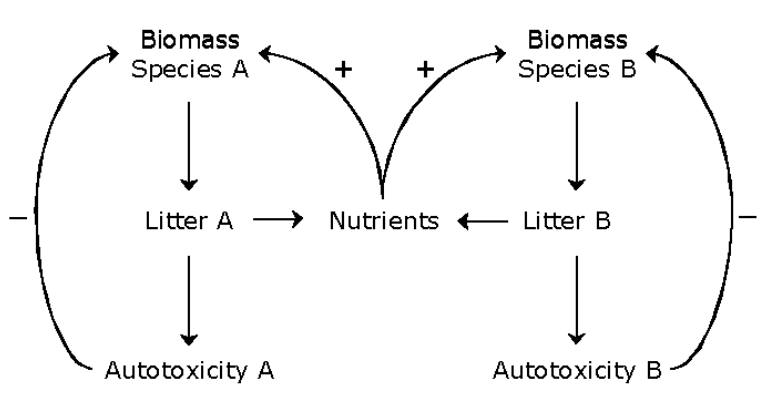

Figure 1. Schematic representation of the feedbacks between decomposition processes and plant growth. Litter decay produces both nutrients and phytotoxic compounds. Autotoxicity implies a negative effect limited to conspecifics.

justified in ignoring it in general frameworks, and they should treat it as a noise or just as a natural history idiosyncrasy. As described below, our position on negative feedback is that its occurrence and intensity are both measurable and predictable according to environmental conditions, and these are crucial to infer plant diversity patterns.

\section{Autotoxicity, litter diversity and species coexistence}

The role of litter diversity on decaying rate has been largely investigated (review in Gartner and Cardon 2004, Hättenschwiler et al. 2005), while few studies exist on its effects on plant growth. Given the process of species-specific autotoxicity, a monospecific stand will build-up in time a negative feedback. Differently, a mixed species stand will produce a diverse litter mixture, which in turn will reduce (dilution) autotoxicity for each species (Fig. 1). Then, despite the unavoidable detrimental effect at the individual scale, the negative feedback can generate a positive effect at the community level, thus sustaining the maintenance of species diversity that overcomes the cost of a higher inter-specific competition for resources. Interestingly, under these assumptions, competitive effects occur on a short-term scale, but positive reciprocal species interactions emerge only if all species suffer from negative feedback (Bonanomi et al. 2005a).

\section{Relation between litter-decaying rate and autotoxicity strength}

Temperature, moisture and nutrients are the most important limiting factors of litter decomposition (Gholz et al. 2000, Berg and McClaugherty 2003). Litter-decaying rate increases with temperature by a $\mathrm{Q}_{10}$ value (the factor by which a $10^{\circ} \mathrm{C}$ increase in temperature will increase decomposition rate) often greater than 2, although $\mathrm{Q}_{10}$ var- 


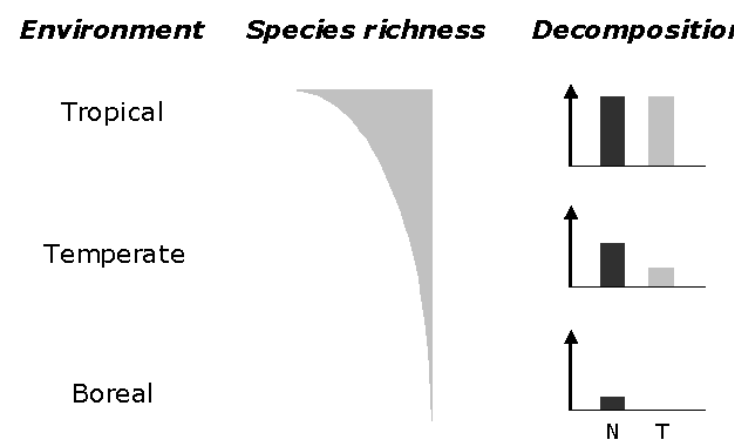

Figure 2. Predicted relationship between litter decaying-rate and nutrients $(\mathrm{N})$ and phytotoxicity $(\mathrm{T})$ released along a gradient of species richness in different environments. The height of bars is proportional to process intensity.

ies in relation to litter type (Fierer et al. 2005). Consequently, litter decomposition rate widely differs among ecosystems, and with the same litter quality and moisture level, the decay-rate progressively decreases from tropical to temperate and boreal forest (Vitousek and Sanford 1986, Aerts 1997, Berg and McClaugherty 2003).

We suggest that litter autotoxicity decreases exponentially with the litter decaying-rate (Fig. 2). According to this assumption, at community level a negligible autotoxic effect can be predicted in boreal forests where decomposition is limited by temperature, while the strongest levels of autotoxicity should be found in tropical forests where optimal decomposition conditions occur.

\section{Nutrients cycle tightness, soil fertility and the impact of litter autotoxicity}

The predicted impact of autotoxicity cannot be related only to litter decay-rate, but also to the nutrient cycling pathway in different ecosystems. In tropical tierra firma forests, litterfall and its decay-rate are very high, making plant litter the most important source for plant mineral nutrition. In these systems, waste production and resource uptake are tightly coupled in space and time, with a very high expected autotoxicity impact. At the opposite extreme, there are ecosystems with completely open nutrient cycle, i.e., mineral nutrition of a species is decoupled from the decaying litter of its own conspecific. Examples of this latter case includes communities in regularly water flushed systems such as stands of perennial species in wetlands and marshes, floating plants and riparian forests in fresh water, and mangrove forests, seagrass and seaweed beds and kelp forests in salt water. In these systems, nutrition is primarily related to the concentration of nutrients in water (and/or in newly accreted soil), consequently the expected impact of negative feedback due to litter autotoxicity should be almost irrelevant. Management strategies aimed at overcoming negative feedback in agro-ecosystems provide an interesting parallelism with the above described idea. Human-managed monocultures can only be sustained by decoupling the resource acquirement from autotoxic litter, which is achieved either by crop residues removal (e.g. burning, selective removal etc.) or mixing the residues through either crop rotation or consociation.

The soil mineral fertility should also be taken into account to predict autotoxicity impact. In many tropical forests, plants cannot rely on mineral soil nutrients. This usually occurs on highly leached oxisols with very low cation exchange capacity and limited nutrients derived by the weathering of parent material (Vitousek and Sanford 1986). In these conditions, trees often produce root mats above the mineral soil directly foraging within the litter layer (Jordan 1982, 1985). Here, the co-occurrence of nutrients and autotoxicity can constrain plant performances when growing in monospecific stands. Moreover, the high rainfall, sometimes exceeding $8000 \mathrm{~mm} \mathrm{year}^{-1}$ (Richards 1996; Givnish 1999), will exacerbate this limiting effect because, under such conditions, plants are necessarily forced to take up nutrients rapidly before their leaching. An increased autotoxic impact can be expected in proportion to the rainfall amount in infertile, highly weathered soils in the tropics. Differently, as soil mineral fertility increases a progressive reduction of the impact of negative feedback due to autotoxicity can be predicted. The rationale behind this hypothesis is that in fertile soil plant roots and decaying litter are spatially segregated (roots preferably feed in the underlying rich soil), thus reducing or even annulling the constraints to plant growth.

Finally, a notable exception is the nutrient poor soils developed in waterlogged and stagnant water (e.g., some swamp tropical forests). In these anaerobic or poorly aerobic conditions, organic matter decomposition follows a complete different pathway (Ponnamperuma 1972), with permanent phytotoxicity, independent by the litter type (Bonanomi et al. 2006). In these conditions, high litter phytotoxic stress, irrespectively of the litter diversity level that can be expected.

\section{Predicted species richness patterns}

The patterns of species richness predicted by the litter autotoxicity hypothesis are summarized below.

\section{Latitudinal and altitudinal species richness patterns}

According to our functional representation, the first predicted pattern is an increase of species richness with 
the litter decaying-rate, which related to both latitude and altitude, and changes in temperature. Interestingly, and in sharp contrast with terrestrial plants, aquatic communities are not predicted to show this latitudinal gradient in species richness. Indeed, floating plants (Eichhornia crassipes (Mart.) Solms., Lemna spp., Pistia spp. etc.), perennial species in wetlands and marshes (Phragmites australis (Cav.) Trin., Spartina spp., Typha spp. etc.), gallery (Mora spp., Tabebuia spp. etc) and mangrove forests (Avicennia spp., Nypa fruticans Wurmb., Rhizophora spp. etc), seagrass (Posidonia spp., Thalassia spp., Zostera spp. etc), seaweed and kelp forests (Fucus spp., Laminaria spp., Macrocystis pyrifera (L.) C. A. Agardh etc), both in salt and freshwater, mostly form monospecific stands, irrespectively of the latitudinal level. While the reasons of this pattern remain enigmatic in the light of previous theory (Willig et al. 2003), this is highly coherent with the litter autotoxicity hypothesis. In aquatic environments, the mineral nutrition is almost completely decoupled from decaying of conspecific litter, thus annulling the autotoxic impact. It is noteworthy, as mentioned before, that not a single case of negative feedback could be found in aquatic systems (Appendix 1). Moreover, periodical die-back due to litter autotoxicity (Armstrong and Armstrong 2001) has been observed in terrestrial flushed systems, but only after changes (reductions) in water regimes, presumably not allowing the removal of decaying litter.

Differences in species richness between communities within the tropics. Species richness at community level varies dramatically within the tropics, especially for tree species. According to our theory, this variability can be related to two variables: mineral soil fertility and rainfall amount. We predict an inverse relationship between species richness and soil fertility, but for the systems with stagnant water where a low diversity and productivity is expected due to the persistent litter phytotoxic stress. The effect of rainfall on species richness is dependent on the levels of soil fertility and nutrient cycle tightness, with a progressive increase of plant diversity with rainfall in infertile highly weathered soils.

\section{Richness-productivity relationship}

The litter autotoxic hypothesis also provides a new promising interpretation key for the long debated richness-productivity relationship (Waide et al. 1999, Gillman and Wright 2006). Species richness will be positively related with productivity only where nutrient cycling is rapid and tightly coupled in space and time with litter decomposition. On the other hand, our hypothesis predicts very productive but monospecific stand in aquatic and flooded (but flushed) terrestrial systems. From this view, ecosystem productivity (in constant environmental conditions) is strictly dependent on high species richness in systems characterized by a closed and rapid nutrient cycle. Differently, ecosystem productivity will progressively be less dependent on species richness as the litter decayingrate declines and/or plant nutrition is progressively decoupled, either in space or time, from the litter decomposition of conspecifics.

\section{Conclusions: species richness is determined by waste-resource dynamics, not only by resource dynamics}

The prevailing scientific consensus relates plant species richness to resource availability in relation to disturbance, biotic interactions and environmental gradients. However, these frameworks fail in predicting species richness at community scale in relation to temperature (i.e. latitudinal and altitudinal gradients), rainfall level, soil fertility and, therefore, to ecosystem productivity. Focusing on resource-waste rather than resource-only dynamics provides a putative explanation for the high species diversity of environments where either litter decomposition is rapid and plant roots feed into the litter layer, and for the high species dominance in communities where litter decomposition is slow and/or autotoxic litter are removed from the nutrient cycle pathway. Since the rate of litter decomposition is related to temperature and moisture, this mechanism provides an explanation for the latitudinal and altitudinal (climatic) distribution of plant richness and for the presence of stable monospecific stands, independently of climatic conditions, in systems where plant nutrition remains decoupled from the waste products. The autotoxic hypothesis is the only one potentially capable to explain both very high and very low species richness within the tropics. However, we are not saying that autotoxic negative feedback is the only mechanism producing the patterns of species richness. Indeed, its integration with other frameworks such as the intermediate-disturbance hypothesis (Connell 1978) and the immigration/extinction balance theory (McArthur and Wilson 1967), does produce an improved theoretical background to understand biodiversity. Without the inclusion of the litter autotoxicity processes, species richness patterns cannot be adequately understood and predicted. Differently from most other theories, our new model produces a frame of predictions which are scientifically verifiable because it is based on processes explicitly functional and on their mechanistic relation with environmental factors. 


\section{References}

Aerts, R. 1997. Climate, leaf litter chemistry and leaf litter decomposition in terrestrial ecosystems: a triangular relationship. Oikos 79:439-449.

Armstrong, J. and W. Armstrong. 2001. An overview of the effects of phytotoxins on Phragmites australis in relation to die-back. Aquatic Botany 69:251-268.

Berendse, F. 1994. Litter decomposability - a neglected compound of plant fitness. J. Ecol. 82:187-190.

Berg, B. and C. McClaugherty. 2003. Plant litter: decomposition, humus formation, carbon sequestration. Springer-Verlag, Berlin, Germany.

Bertness, M.D. and G.H. Leonard. 1997. The role of positive interactions in communities: lesson from intertidal habitats. Ecology 78:1976-1989.

Bever, J.D., M. Westover and J. Antonovics. 1997. Incorporating the soil community into plant population dynamics: the utility of the feedback approach. J. Ecol. 85:561-573.

Bever, J.D. 1994. Feedback between plants and their soil communities in an old field community. Ecology 75:1965-1977.

Blum, U., S.R. Shafer and M.E. Lehman. 1999. Evidence for inhibitory allelopathic interactions involving phenolic acids in field soils: concepts vs an experimental model. Critical Reviews in Plant Science 18:673-693.

Bonanomi, G. and S. Mazzoleni. 2005. Soil history affects plant growth and competitive ability in herbaceous species. Соттиnity Ecol. 6:23-28.

Bonanomi, G., F. Giannino and S. Mazzoleni. 2005a. Negative plant-soil feedback and species coexistence. Oikos 111:311321.

Bonanomi, G., M. Rietkerk, S.C. Dekker and S. Mazzoleni. 2005b. Negative plant-soil feedback and positive species interaction in a herbaceous plant community. Plant. Ecol. 181:269-278.

Bonanomi, G., M.G. Sicurezza, S. Caporaso, A. Esposito and S. Mazzoleni. 2006. Phytotoxicity dynamics of decaying plant materials. New Phytol. 169:571-578.

Chesson, P. 2000. Mechanisms of maintenance of species diversity. Annu. Rev. Ecol. Syst. 31:343-366.

Conn, C. and J. Dighton 2000. Litter quality influences on decomposition, ectomycorrhizal community structure and mycorrhizal root surface acid phosphatase activity. Soil Biology and Biochemistry 32:489-496.

Connell, J.H. 1978. Diversity in tropical rain forest and coral reefs. Science 199:1302-1310.

Darwin C. 1862. The Voyage of the Beagle. Doubleday, Garden City, NJ.

De Rooij-van Der Goes, P.C.E.M. 1995. The role of plant-parasitic nematodes and soil-borne fungi in the decline of Ammophila arenaria L. Link. New Phytol. 129:661-669.

Ehrenfeld, J.G., B. Ravit and K. Elgersma. 2005. Feedback in the plant-soil system. Annual Review of Environment and Resources $30: 75-115$.

Fierer, N., J.M. Craine, K. McLauchlan and J.P. Shimel 2005. Litter quality and the temperature sensitivity of decomposition. Ecology 86:320-326.

Gartner, T.B. and Z.G. Cardon. 2004. Decomposition dynamics in mixed-species leaf litter. Oikos 104:230-246.

Gholz, H.L., D.A. Wedin, S.M. Smitherman, M.E. Harmon and W.J. Parton. 2000. Long-term dynamics of pine and hardwood litter in contrasting environments: toward a global model of decomposition. Global Change Biology 6:751-765.

Gillman, L.N. and S.D. Wright. 2006. The influence of productivity on the species richness of plants: a critical assessment. Ecology 87:1234-1243.

Givnish, T.J. 1999. On the causes of gradients in tropical tree diversity. J. Ecol. 87:193-210.

Harper, J.L. 1977. Population Biology of Plants. Academic Press, London, UK

Hättenschwiler, S., A.V. Tiunov and S. Scheu. 2005. Biodiversity and litter decomposition in terrestrial ecosystems. Annu. Rev. Ecol. Evol. Syst. 36:191-218.

Hodge, H. 2004. The plastic plant: root responses to heterogeneous supplies of nutrients. New Phytol. 162:9-24.

Hubbell, S.P. 2001. A Unified Theory of Biodiversity and Biogeography. Princeton University Press, Princeton, New Jersey, USA.

Huston, M.A. 1994. Biological Diversity: The Coexistence of Species on Changing Landscape. Cambridge Univ. Press.

Hutchinson, G.E. 1958. Homage to Santa Rosalia, or why are there so many species of animals? Am. Nat. 93:145-159.

Inderjit and R.M. Callaway. 2003. Experimental designs for the study of allelopathy. Plant and Soil 256:1-11.

Jackson, R.B. and M.M. Caldwell. 1989. The timing and degree of root proliferation in fertile-soil microsites for three cold-desert perennials. Oecologia 81:149-153.

Janzen, D.H. 1970. Herbivores and the numbers of tree species in tropical forests. Am. Nat. 104:501-528.

Jordan, C.F. 1982. The nutrient balance of an Amazonian rain forest. Ecology 63:647-654.

Jordan, C.F. 1985. Nutrient cycling in tropical forest ecosystems. principles and their application in management and conservation. Wiley, Chichester.

Kardol, P., N.J. Cornips, M.M.L. van Kempen, J.M.T. Bakx-Schotman and W.H. van der Putten. 2007. Microbe-mediated plantsoil feedback causes historical contingency effects in plant community assembly. Ecol. Monog. 77: 147-162.

Kiers, E., C. Lovelock, E. Krueger, and E.A. Herre. 2000. Differential effects of tropical arbuscular mycorrhizal fungal inocula on root colonization and tree seedling growth: implications for tropical forest diversity. Ecology Letters 3:106-113.

Klironomos, J.N. 2002. Feedback with soil biota contributes to plant rarity and invasiveness in communities. Nature 417:67-70.

Makino, T, T. Takahashi, Y. Sakurai and M. Nanzyo. 1996. Influence of soil chemical properties on adsorption and oxidation of phenolic acids in soil suspension. Soil Science and Plant Nutrition 42:867-879.

McArthur, R.H. and E.O. Wilson. 1967. The theory of island biogeography. Princeton University Press, N.J.

McNaughton, S.J. 1968. Autotoxic feedback in relation to germination and seedling growth in Typha latifolia. Ecology 49:367369.

Miller, D.A. 1996. Allelopathy in forage crop system. Agron. J. 36:854-859.

Oremus, P.A.I. and H. Otten. 1981. Factors affecting growth and nodulation of Hippophae rhamnoides L. ssp. rhamnoides in soils from two successional stages of dune formation. Plant Soil 63:317-331

Packer, A. and K. Clay. 2000. Soil pathogens and spatial patterns of seedling mortality in a temperate tree. Nature 404:278-280. 
Palmer, M.W. 1994. Variation in species richness: towards a unification of hypotheses. Folia Geobotanica et Phytotaxonomica 29:511-530.

Perry, L.G., G.C. Thelen, W.M. Ridenour, T.L. Weir, R.M. Callaway, M.W. Paschke and J.M. Vivanco. 2005. Dual role for an allelochemical: $( \pm)$-catechin from Centaurea maculosa root exudates regulates conspecific seedling establishment. J. Ecol. 93:1126-1135.

Ponnamperuma, F.N. 1972. The chemistry of submerged soils. $A d v$. Agron. 24:29-96.

Rice, E. L. 1984. Allelophaty. 2nd ed. Academic Press, London.

Richards, P.W. 1996. The Tropical Rain Forest: An Ecological Study. 2nd edn. Cambridge Univ. Press, Cambridge.

Singh, H.P., R.D. Batish and K.R. Kohli. 1999. Autotoxicity: concept, organisms and ecological significance. Crit. Rev. Plant. Sci. 18:757-772.

Streng, R.D., J.S. Glitzenstein and P.A. Harcombe. 1989. Woody seedling dynamics in an east Texas floodplain in forest. Ecol. Monogr. 59:177-204.

Tilman, D. 1994. Competition and biodiversity in spatially structured habitats. Ecology 75:2-16.

Valencia, R., H. Balslev and C.G. Paz y Miño. 1994. High tree alpha-diversity in Amazonian Ecuador. Biodiversity and Conservation 3:21-28.

Van der Putten, W.H. 2003. Plant defense belowground and spatiotemporal processes in natural vegetation. Ecology 84:22692280 .

Van der Putten, W.H., C. Van Dijk and B.A.M. Peters. 1993. Plantspecific soil-borne diseases contribute to succession in foredune vegetation. Nature 362:53-56.
Vitousek, P.M. and R.L. Jr. Sanford. 1986. Nutrient cycling in moist tropical forest. Annu. Rev. Ecol. Syst. 17: 137-167.

Waide, R.B., M.R. Willig, C.F. Steiner, G. Mittelbach, L. Gough, S.I. Dodson, G. Juday and R. Parmenter. 1999. The relationship between productivity and species richness. Annu. Rev. Ecol. Syst. 30:257-300.

Webb, L.J., J.G. Tracey and K.P. Haydock. 1967. A factor toxic to seedling of the same species associated with living roots of the non-gregarious subtropical rain forest tree Grevillea robusta. J. Appl. Ecol. 4:13-25.

Willig, M.R., D.M. Kaufman and R.D. Stevens. 2003. Latitudinal gradients of biodiversity: pattern, process, scale, and synthesis. Annu. Rev. Ecol. Evol. Syst. 34: 273-309.

Wills, C., R. Condit, R.B. Foster and S.P. Hubbell. 1997. Strong density- and diversity-related effects help to maintain tree species diversity in a neotropical forest. Proc. Natl. Acad. Sci. U.S.A. 94:1252-1257.

Zucconi, F. 1996. Declino del suolo e stanchezza del terreno. Spazio Verde, Padova.

Received May 14, 2007 Revised June 7, 2007 Accepted June 14, 2007

Appendix 1. List of experimental cases of plant-soil negative feedback from different ecosystems. The electronic version can be downloaded from the web site of the journal at www.akademiai.com. 